\title{
Transmission of Onychomycosis and Dermatophytosis between Household Members: A Scoping Review
}

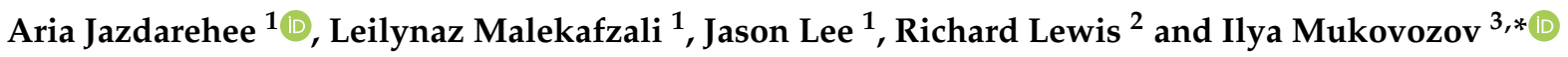 \\ 1 Department of Medicine, University of British Columbia, Vancouver, BC V6T 1Z4, Canada; \\ ariajaz@student.ubc.ca (A.J.); leilynaz@student.ubc.ca (L.M.); dgl@student.ubc.ca (J.L.) \\ 2 Kamloops Dermatology, Kamloops, BC V2C 2H3, Canada; dickiderm@shaw.ca \\ 3 Department of Dermatology and Skin Science, University of British Columbia, Vancouver, BC V5Z 4E8, Canada \\ * Correspondence: ilya.mukovozov@alumni.ubc.ca
}

Citation: Jazdarehee, A.; Malekafzali, L.; Lee, J.; Lewis, R.; Mukovozov, I. Transmission of Onychomycosis and Dermatophytosis between Household Members: A Scoping Review. J. Fungi 2022, 8, 60. https://doi.org/10.3390/ jof8010060

Academic Editors: Mohamad Goldust and Jacek C. Szepietowski

Received: 10 December 2021

Accepted: 4 January 2022

Published: 6 January 2022

Publisher's Note: MDPI stays neutral with regard to jurisdictional claims in published maps and institutional affiliations.

Copyright: (c) 2022 by the authors. Licensee MDPI, Basel, Switzerland. This article is an open access article distributed under the terms and conditions of the Creative Commons Attribution (CC BY) license (https:// creativecommons.org/licenses/by/ $4.0 /)$.

\begin{abstract}
Onychomycosis is a common fungal infection of the nail, caused by dermatophytes, non-dermatophytes, and yeasts. Predisposing factors include older age, trauma, diabetes, immunosuppression, and previous history of nail psoriasis or tinea pedis. Though many biological risk factors have been well characterized, the role of the environment has been less clear. Studies have found evidence of transmission in $44 \%$ to $47 \%$ of households with at least one affected individual, but the underlying mechanisms and risk factors for transmission of onychomycosis between household members are incompletely understood. A scoping literature review was performed to characterize and summarize environmental risk factors involved in the transmission of onychomycosis within households. A total of 90 papers met the inclusion criteria, and extracted data was analyzed in an iterative manner. Shared household surfaces may harbor dermatophytes and provide sources for infection. Shared household equipment, including footwear, bedding, and nail tools, may transmit dermatophytes. The persistence of dermatophytes on household cleaning supplies, linen, and pets may serve as lasting sources of infection. Based on these findings, we provide recommendations that aim to interrupt household transmission of onychomycosis. Further investigation of the specific mechanisms behind household spread is needed to break the cycle of transmission, reducing the physical and social impacts of onychomycosis.
\end{abstract}

Keywords: onychomycosis; tinea; tinea unguium; household; family; environment; transmission

\section{Introduction}

Onychomycosis is a broad term that encompasses all fungal infections of the nail, including those caused by dermatophytes, non-dermatophytes, and yeasts [1-3]. There are multiple subtypes, including distal/lateral subungual, superficial white, and proximal subungual onychomycosis, among others [4]. Clinical features may include nail discoloration, subungual hyperkeratosis, and onycholysis [1]. Left untreated, complications include local pain, paresthesias, spread of infection, as well as the functional and social impairments of nail dystrophy $[1,5]$. The incidence of onychomycosis is estimated at about $6.5 \%$ amongst Canadians, and onychomycosis is thought to be responsible for approximately $50 \%$ of nail disorders globally [6].

Dermatophytes account for $90 \%$ of onychomycosis cases, and tinea unguium is a term which refers specifically to a dermatophyte infection of the nail $[4,7]$. Common causative agents include Trichophyton rubrum, T. interdigitale, and Epidermophyton floccosum [1,4]. In children, infection with $T$. tonsurans is frequently seen [4]. Though all dermatophytes can cause onychomycosis, infection due to Microsporum spp. is rare [4].

The pathophysiology of dermatophyte infection involves adhesion to the stratum corneum, followed by invasion into the underlying sublayers [8]. Adhesion is facilitated by fibrils on fungal spore cell walls which anchor to host keratinocyte membranes, as 
well as carbohydrate-specific adhesins which recognize mannose and galactose on host cells [8-10]. Following adhesion, spores germinate, forming hyphae that grow in multiple directions, including deeper into the stratum corneum which results in the destruction of subungual structures [9]. The invasion process is facilitated by fungal proteases that hydrolyze extracellular matrix proteins including keratin and collagen, whose breakdown in turn provides nutrients for invading dermatophytes [8,9,11].

Predisposing factors for onychomycosis include older age, trauma, diabetes, immunosuppression, and previous history of nail psoriasis or tinea pedis (athlete's foot) [1] Exposure to humid environments, occlusive footwear, and occupations which involve frequent travel, handwashing, or communal bathing facilities increase the risk of developing onychomycosis $[7,12]$. Studies have found that certain human leukocyte antigen class II genes may influence susceptibility to developing onychomycosis [13-15]. Though many biological risk factors have been well characterized, the role of the environment has been less clear. Of particular interest are the factors that influence transmission of onychomycosis between household members. Previous studies have suggested the risk of onychomycosis transmission in households with one affected member to be between $44 \%$ and $47 \%[16,17]$. Indeed, using molecular techniques, it was shown that individuals within the same household were infected by the same dermatophyte strain, suggesting likely household transmission [16,18]. Proposed mechanisms of transmission between household members include sharing of slippers or even walking on carpets or bathroom floors previously walked on by an affected individual harboring infectious fungal elements [19]. Indeed, studies have found that dermatophytes are able to survive in washed textiles such as socks and contaminated nail polish containers [20,21]. Despite this, studies directly implicating environmental risk factors to transmission of onychomycosis are lacking, and more evidence is required to understand social determinants associated with the development of onychomycosis.

In light of this knowledge gap, we conducted a scoping literature review to characterize and summarize the environmental risk factors involved in the transmission of onychomycosis between individuals within households. A better understanding of the factors contributing to the spread of onychomycosis within households will allow for the development of recommendations which aim to limit household spread. Given the high incidence of onychomycosis and the functional and societal impacts of infection, our findings may play a significant role in reducing the incidence of infection through primary prevention.

\section{Materials and Methods}

Given the paucity of studies directly investigating the spread of onychomycosis among household members, we conducted a scoping literature review for broad assessment of evidence relevant to the topic. A scoping review allows for the systematic mapping of research done in a broad context [22]. Like systematic reviews, scoping reviews require structured, comprehensive searches to produce reproducible results [22]. The protocol for this scoping review was drafted in accordance with the Preferred Reporting Items for Systematic Reviews and Meta-analysis Extension for Scoping Reviews [23].

\subsection{Search Strategy, Study Eligibility Criteria, and Study Selection}

A systematic search of the literature was conducted by combining search terms for onychomycosis and disease transmission using the MEDLINE database (United States National Library of Medicine) through the OVID interface. The search strategy is outlined in Table 1. Studies were deemed eligible for inclusion if they were published in peer-review journals, written in English, and published between 1950 and 2021. Human studies were prioritized, and both primary studies and reviews were included. In vitro and animal studies were excluded. 
Table 1. MEDLINE search strategy.

\begin{tabular}{cc}
\hline Search & Keywords \\
\hline $\mathbf{1}$ & Onychomycos $^{*}$ \\
\hline 2 & tinea unguium $^{*}$ \\
\hline 3 & Dermatophyte $^{*}$ \\
\hline 4 & disease transmission, infectious \\
\hline 5 & transmission \\
\hline 6 & 1 or 2 or 3 \\
\hline 7 & 4 or 5 or 6 \\
\hline 8 & 7 and 8 \\
\hline 9 &
\end{tabular}

The final search results were transferred to COVIDENCE (Melbourne, Australia) (www.covidence.org; last accessed on 1 November 2021) for title, abstract, and full-text screening [24]. Three reviewers (A.J., L.M., J.L.) independently evaluated titles, abstracts, and full texts to identify relevant studies. Disagreements were resolved by consensus and through discussion with the senior reviewer (I.M.).

\subsection{Data Extraction and Synthesis}

Three reviewers (A.J., L.M., J.L.) independently extracted data from eligible studies using a standardized extraction form that included title, authors, year of publication, study population, and key findings. All reviewers evaluated the extracted data and worked together to synthesize the available evidence in an iterative manner. As part of the scoping review methodology, supplemental searches were done to support the findings of our initial literature search. These additional searches were guided by reviewing reference lists of included studies to ensure that all primary studies relevant to our search were captured.

\section{Results}

The search yielded 425 results, 90 of which were deemed relevant for review. Of these, 49 were primary studies, 32 were review papers, and 9 were mixed-method studies. The date of the studies ranged from 1954 to 2020 and they included data on both adult and pediatric populations.

\subsection{Transfer through Shared Surfaces}

Dermatophytes have been found to persist on a variety of surfaces, particularly wet surfaces on which individuals walk barefoot. Multiple species, including T. rubrum and T. mentagrophytes have been isolated from walkways, changing rooms, and foot washing stations in swimming pool facilities, despite regular disinfection with chlorine [25]. Dermatophytes were found to be in greatest concentrations along walkways where people converged, including entrances and exits [26]. Aside from swimming pools, studies have found T. rubrum, T. mentagrophytes, and T. tonsurans on the floors of mosques, wrestling mats, and nursing homes [27-29]. In one nursing home study, T. tonsurans was isolated from $22.8 \%$ of samples collected from various bedroom and bathroom surfaces [30]. Clinically relevant species of dermatophytes have even been isolated from garden soils and beach sand which have been in contact with human feet [31].

Multiple studies have shown that these surfaces may be not only harboring dermatophytes, but also driving transmission of onychomycosis. In an investigation of an outbreak in a long-term care facility in which patients were mostly bedridden with minimal direct interpersonal contact, transmission was attributed to a shared bathtub, in which 9 strains of T. interdigitale were found [29]. In another study, the same dermatophyte species were found within house dust on the floors of affected individuals in 48 of 117 (41\%) cases [32]. 
Raboobee et al. found a higher prevalence of tinea pedis and unguium among individuals who had visited a mosque compared to a control group, and isolated various yeasts and Trichophyton spp. from carpets walked on by affected individuals [33].

The use of slippers or other footwear not shared with other household members may limit dermatophyte spread from shared surfaces. In one study conducted in an Italian military school where individuals wore sandals while showering, only $0.2 \%$ of those tested were found to have onychomycosis [34].

In summary, shared surfaces may harbor dermatophytes and provide sources of infection. Applying these findings to the household environment, dermatophytes may likely be found on wet surfaces, such as patios, balconies, washrooms, showers, and bathtubs. There may also be a high density of dermatophytes in areas of convergence, such as entrances and narrow hallways. Care should be taken to properly disinfect and avoid walking barefoot on these surfaces.

\subsection{Transfer through Shared Equipment}

Aside from shared surfaces, shared equipment may also play a role in the transmission of onychomycosis among family members. Multiple studies have implicated use of shared hair equipment, including combs, hairbrushes, and headrests with the transmission of T. rubrum and T. mentagrophytes, causing tinea capitis $[30,35,36]$. One study conducted in the context of a barber shop found dermatophytes and non-dermatophytes, primarily Aspergillus spp., on $24.4 \%$ of combs, hairbrushes, shaving brushes, and chair headrests tested [35].

Other studies investigating dermatophytosis in general have suggested that sharing soaps, towels, bedding, and general articles of clothing may be implicated in dermatophyte transmission, and individuals are at greatest risk when there is any skin trauma or breaks in skin barrier $[37,38]$. Though this data relates to dermatophyte spread in general, it is clinically relevant for development of onychomycosis because studies have shown that $30 \%$ of cutaneous dermatophyte infections have nail involvement [39]. Development of these infections, particularly tinea pedis, has been established as risk factors for developing onychomycosis [39,40].

Relating more specifically to the feet and toenails, studies have cited sharing of sandals, slippers, and footwear as risk factors for transmission of onychomycosis. Indeed, E. floccosum, T. rubrum, and T. mentagrophytes have been found on the surfaces of slippers, sandals, and socks in multiple studies [41-44]. Methods such as ultraviolet radiation and ozone have been shown to reduce fungal burden on these types of footwear [44].

Sharing of nail polish may also promote transmission of onychomycosis. One study found that T. rubrum is able to survive in nail polish for 60 days at $25^{\circ} \mathrm{C}$ [21]. There have been no studies examining fungal burden on other nail equipment such as nail clippers, files, or scissors, but these may also be implicated with spread. Nail trauma, including micro traumas following manicures or pedicures, may increase the risk of infection with these shared tools [45].

\subsection{Persistence of Fungi within the Household Environment}

In addition to the mechanisms of fungal spread discussed above, the persistence of organisms within the household environment may promote reinfection or provide sources of infection for other household members. Indeed, dermatophytes have been found to persist in the household environment for up to 18 months [46].

Multiple studies have demonstrated the ability of fungi to persist on household cleaning supplies. Ekowati et al. found 15 clinically relevant fungi species on 21 of 24 (88\%) samples of cleaning supplies, including mops, scrubbers and wipes [26]. In many cases, the same species on the cleaning supplies were also isolated from floors, and the authors argue that improperly disinfected cleaning tools may promote fungal spread [26]. Other studies have found M. gypseum and T. mentagrophytes, common agents of onychomycosis, in up to 
$48.4 \%$ of household vacuum cleaners tested $[47,48]$, and it has been argued that vacuums without proper filters may result in further dissemination of fungi and spores [49].

Textiles, particularly clothing and bedding, may also harbor fungal pathogens, and studies have previously implicated textiles with human infection $[38,50]$. The warm environment and presence of desquamated keratinocytes provides for ideal growing conditions for fungi [51]. Multiple studies have shown persistence of dermatophytes on clothing, particularly socks, despite regular laundering $[20,44]$. Indeed, yeast and fungi have been shown to withstand washing temperatures below $40^{\circ} \mathrm{C}$ and $60^{\circ} \mathrm{C}$, respectively [52,53]. This has implications for cold-water laundering, and studies have also shown that inadequately cleaned washing machines spread fungi to previously sterile textiles [54,55].

Pets may also play a role by harboring fungi, and pet ownership has been cited as a risk factor for developing onychomycosis [56]. In one study, contact with cats or dogs was reported in 39.5\% of those with dermatophytosis [57]. M. canis has most commonly been reported in cats and dogs, and human dermatophyte infections have been directly linked to these animals [58,59]. Small rodents such as guinea pigs have been known to harbor dermatophytes [60]. In one study of 101 guinea pigs with dermatophytosis, 98 (97\%) were positive for T. mentagrophytes and $24 \%$ of households had family members with clinical signs of dermatophytosis, with greater involvement in children than adults [61]. There have also been multiple reported outbreaks of T. benhamiae and T. rubrum in humans attributed to small rodents, including guinea pigs and rabbits, through genotyping techniques $[60,62,63]$. In many cases, pets were brought into the household just weeks prior to development of clinical symptoms in adults, which reinforces the need to properly examine new pets entering the household to prevent introduction of fungal pathogens [61]. In summary, dermatophytes are able to persist within the household environment, namely on cleaning supplies, textiles, and pets.

\section{Discussion}

It is well established that individuals with onychomycosis are at risk of spreading infection to other household members. The proportion of households demonstrating spread of onychomycosis following infection of an initial member has been found to be between $44 \%$ and $47 \%$ [16,17]. Molecular techniques have provided further support for household spread by identifying the same strains of dermatophytes in affected members of a household [16,18]. Though theories behind household transmission have been suggested, there have been no studies formally investigating the mechanisms behind transmission. Our findings suggest that shared surfaces, shared equipment, and persistence within the household may present opportunities for reinfection and spread of onychomycosis among household members.

The findings of our review suggest that indirect transmission, rather than direct contact, between household members plays a key role in the spread of onychomycosis within households. We did not find any data implicating direct human-human transmission within the household. Interestingly, the prevalence of infection appears to be higher between spouses and children compared to those marrying into the family, highlighting the genetic predisposition underlying infection [15]. Aside from genetic predisposition, household members with diabetes, psoriasis, poor peripheral circulation, or immunosuppression, or smoking habits may be at greater risk of developing infection [7].

Our study findings of the possible mechanisms for household transmission of onychomycosis are summarized in Figure 1. Based on these findings, a list of recommendations that aim to interrupt transmission of onychomycosis in the household setting is proposed and summarized in Table 2. In addition to these recommendations, measures should be taken at the individual level to prevent infection, including maintaining foot hygiene and wearing non-occlusive shoes. Many of these recommendations are summarized in table 6 of Gupta et al. [7]. 

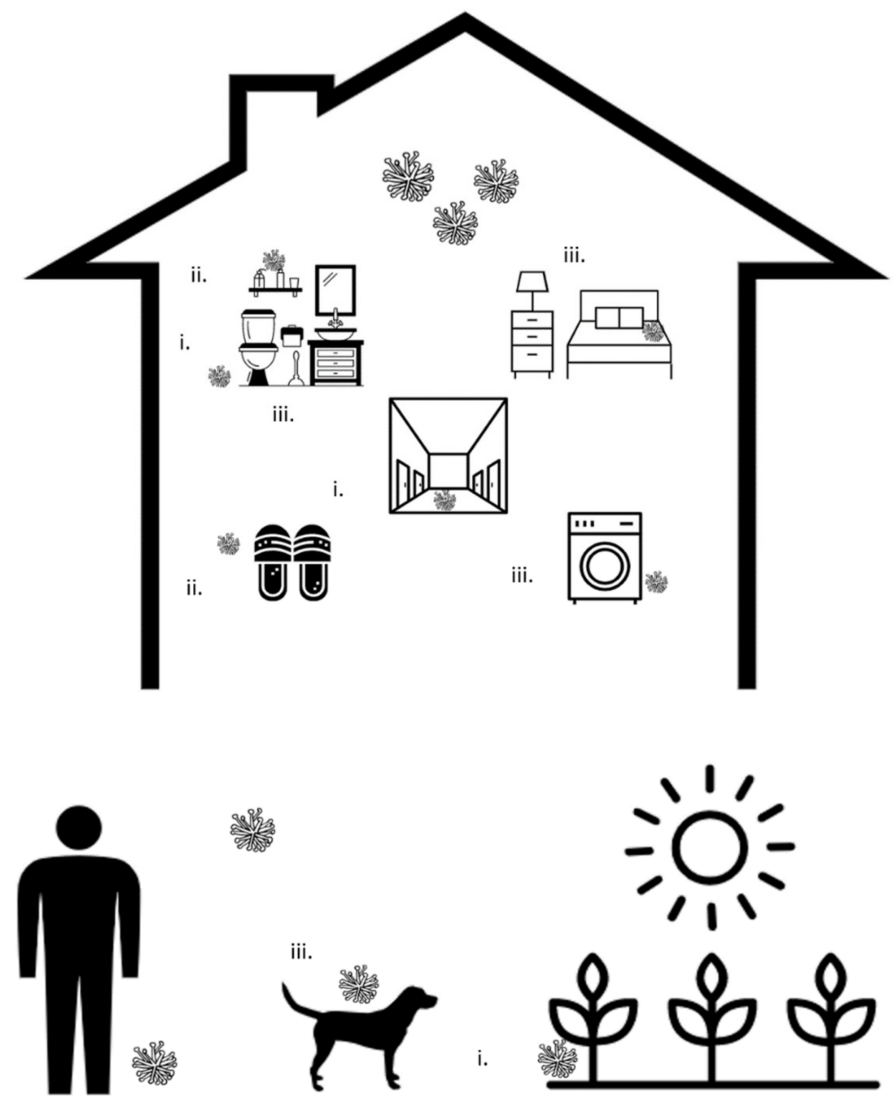

Figure 1. Summary of potential pathways involved in the household transmission of onychomycosis: (i) Shared surfaces within the household may harbor fungi and provide sources for transmission. Possible surfaces include patios, balconies, washrooms, showers, bathtubs, and areas of convergence such as entrances and hallways; (ii) Shared household equipment, including footwear, bedding, and nail tools, may facilitate transmission of onychomycosis; (iii) Fungi may also persist within the household environment, on cleaning tools, linen, and pets, serving as ongoing sources of infection.

Table 2. Recommendations to limit the household spread of onychomycosis.

\begin{tabular}{c}
\hline Minimizing Spread from Shared Surfaces \\
\hline Properly disinfect floors and bathtubs, particularly in high traffic areas (e.g., entrances, hallways) \\
Wear socks or slippers around the house \\
Regularly wash feet and wipe them dry \\
Minimizing spread from shared equipment \\
\hline Minimize sharing of slippers or socks, and disinfect slippers regularly \\
Minimize sharing of nail polish and nail tools (clippers, scissors, files) \\
Disinfect nail tools before and following use \\
\hline Minimizing persistence of dermatophytes in the household environment \\
\hline Use single-use cleaning supplies or regularly disinfect cleaning tools to prevent the spread of fungi \\
Launder textiles at temperatures $>60^{\circ} \mathrm{C}$ \\
Regularly disinfect laundry machines \\
Maintain hygiene of pets
\end{tabular}

Breaking the cycle of household dermatophyte transmission may not only prevent onychomycosis, but also limit asymptomatic carriage which may predispose one to onychomycosis. One study found that household members are able to asymptomatically carry and spread dermatophytes for up to two months [36]. Children may play a key role in asymptomatic transmission, and it has been argued that children are more likely to harbor dermatophytes due to close contact with floors and soils $[47,64]$. One study found 
dermatophytosis to be asymptomatic in $16 \%$ of children [64], and another found dermatophyte carriage in $86 \%$ of family members with one affected child with tinea pedis [65]. Recent advances in the diagnosis of onychomycosis may facilitate the detection of cases in asymptomatic individuals in order to better characterize patterns of transmission among household members [66].

Given the paucity of studies directly exploring the mechanisms behind household transmission of onychomycosis, this study is limited to a broad overview of factors which may contribute to this spread. A limitation to our findings is that they are based on studies conducted on transmission of other dermatophytes resulting in human infection at other body sites, such as tinea capitis. This evidence is clinically relevant, however, given the similar mechanisms of dermatophyte infections across body sites. Other limitations reflect the scoping review design, and include the lack of study quality appraisal and possible selection bias of the papers included in the analysis.

\section{Conclusions}

Our study highlights several factors which may facilitate the persistence and spread of onychomycosis among household members. Further investigation of the specific mechanisms behind household spread is needed to break the cycle of infection and reinfection, which would reduce the physical and social impacts of onychomycosis.

Author Contributions: All authors were involved in the conceptual design of this review. A.J., L.M. and J.L. conceived the search strategy. All authors, A.J., L.M., J.L., R.L. and I.M., were involved in the screening, extraction, and analysis processes. All authors have read and agreed to the published version of the manuscript.

Funding: This research received no external funding.

Institutional Review Board Statement: Not applicable.

Informed Consent Statement: Not applicable.

Conflicts of Interest: The authors declare no conflict of interest.

\section{References}

1. Lipner, S.R.; Scher, R.K. Onychomycosis: Clinical Overview and Diagnosis. J. Am. Acad. Dermatol. 2019, 80, 835-851. [CrossRef] [PubMed]

2. Ghannoum, M.A.; Hajjeh, R.A.; Scher, R.; Konnikov, N.; Gupta, A.K.; Summerbell, R.; Sullivan, S.; Daniel, R.; Krusinski, P.; Fleckman, P.; et al. A Large-Scale North American Study of Fungal Isolates from Nails: The Frequency of Onychomycosis, Fungal Distribution, and Antifungal Susceptibility Patterns. J. Am. Acad. Dermatol. 2000, 43, 641-648. [CrossRef] [PubMed]

3. Hay, R.J.; Baran, R. Onychomycosis: A Proposed Revision of the Clinical Classification. J. Am. Acad. Dermatol. 2011, 65, 1219-1227. [CrossRef] [PubMed]

4. Bolognia, J.L.; Schaffer, J.V.; Cerroni, L. Dermatology; Elsevier: Amsterdam, The Netherlands, 2017; ISBN 978-0-7020-6275-9.

5. Gupta, A.K.; Mays, R.R. The Impact of Onychomycosis on Quality of Life: A Systematic Review of the Available Literature. Skin Appendage Disord. 2018, 4, 208-216. [CrossRef]

6. Gupta, A.K.; Jain, H.C.; Lynde, C.W.; MacDonald, P.; Cooper, E.A.; Summerbell, R.C. Prevalence and Epidemiology of Onychomycosis in Patients Visiting Physicians' Offices: A Multicenter Canadian Survey of 15,000 Patients. J. Am. Acad. Dermatol. 2000, 43, 244-248. [CrossRef] [PubMed]

7. Gupta, A.K.; Stec, N.; Summerbell, R.C.; Shear, N.H.; Piguet, V.; Tosti, A.; Piraccini, B.M. Onychomycosis: A Review. J. Eur. Acad. Dermatol. Venereol. 2020, 34, 1972-1990. [CrossRef] [PubMed]

8. Kaufman, G.; Horwitz, B.A.; Duek, L.; Ullman, Y.; Berdicevsky, I. Infection Stages of the Dermatophyte Pathogen Trichophyton: Microscopic Characterization and Proteolytic Enzymes. Med. Mycol. 2007, 45, 149-155. [CrossRef] [PubMed]

9. Yue, X.; Li, Q.; Wang, H.; Sun, Y.; Wang, A.; Zhang, Q.; Zhang, C. An Ultrastructural Study of Trichophyton Rubrum Induced Onychomycosis. BMC Infect. Dis. 2015, 15, 532. [CrossRef]

10. Esquenazi, D.; Alviano, C.S.; de Souza, W.; Rozental, S. The Influence of Surface Carbohydrates during in Vitro Infection of Mammalian Cells by the Dermatophyte Trichophyton Rubrum. Res. Microbiol. 2004, 155, 144-153. [CrossRef]

11. Baldo, A.; Monod, M.; Mathy, A.; Cambier, L.; Bagut, E.T.; Defaweux, V.; Symoens, F.; Antoine, N.; Mignon, B. Mechanisms of Skin Adherence and Invasion by Dermatophytes. Mycoses 2012, 55, 218-223. [CrossRef]

12. Fenstermacher, K.; Hudson, B.T. Practice Guidelines for Family Nurse Practitioners E-Book; Elsevier Health Sciences: Amsterdam, The Netherlands, 2019; ISBN 978-0-323-59481-3. 
13. Carrillo-Meléndrez, H.; Ortega-Hernández, E.; Granados, J.; Arroyo, S.; Barquera, R.; Arenas, R. Role of HLA-DR Alleles to Increase Genetic Susceptibility to Onychomycosis in Nail Psoriasis. Skin Appendage Disord. 2016, 2, 22-25. [CrossRef]

14. Asz-Sigall, D.; López-García, L.; Vega-Memije, M.E.; Lacy-Niebla, R.M.; García-Corona, C.; Ramírez-Rentería, C.; Granados, J.; Villa, A.; Ameen, M.; Arenas, R. HLA-DR6 Association Confers Increased Resistance to T. Rubrum Onychomycosis in Mexican Mestizos. Int. J. Dermatol. 2010, 49, 1406-1409. [CrossRef]

15. Faergemann, J.; Correia, O.; Nowicki, R.; Ro, B.-I. Genetic Predisposition-Understanding Underlying Mechanisms of Onychomycosis. J. Eur. Acad. Dermatol. Venereol. 2005, 19, 17-19. [CrossRef]

16. Ghannoum, M.A.; Mukherjee, P.K.; Warshaw, E.M.; Evans, S.; Korman, N.J.; Tavakkol, A. Molecular Analysis of Dermatophytes Suggests Spread of Infection Among Household Members. Cutis 2013, 91, 237-245.

17. English, M.P. Trichophyton Rubrum Infection in Families. Br. Med. J. 1957, 1, 744-746. [CrossRef]

18. Suzuki, S.; Mano, Y.; Furuya, N.; Fujitani, K. Molecular Epidemiological Analysis of the Spreading Conditions of Trichophyton in Long-Term Care Facilities in Japan. Jpn. J. Infect. Dis. 2018, 71, 462-466. [CrossRef]

19. El Fekih, N.; Belghith, I.; Trabelsi, S.; Skhiri-Aounallah, H.; Khaled, S.; Fazaa, B. Epidemiological and Etiological Study of Foot Mycosis in Tunisia. Actas Dermo-Sifiliográficas 2012, 103, 520-524. [CrossRef]

20. Bonifaz, A.; Vázquez-González, D.; Hernández, M.A.; Araiza, J.; Tirado-Sánchez, A.; Ponce, R.M. Dermatophyte Isolation in the Socks of Patients with Tinea Pedis and Onychomycosis. J. Dermatol. 2013, 40, 504-505. [CrossRef]

21. Klafke, G.B.; da Silva, R.A.; de Pellegrin, K.T.; Xavier, M.O. Analysis of the Role of Nail Polish in the Transmission of Onychomycosis. An. Bras. Dermatol. 2018, 93, 930-931. [CrossRef]

22. Sucharew, H.; Sucharew, H. Methods for Research Evidence Synthesis: The Scoping Review Approach. J. Hosp. Med. 2019, 14, 416-418. [CrossRef]

23. Tricco, A.C.; Lillie, E.; Zarin, W.; O’Brien, K.K.; Colquhoun, H.; Levac, D.; Moher, D.; Peters, M.D.J.; Horsley, T.; Weeks, L.; et al. PRISMA Extension for Scoping Reviews (PRISMA-ScR): Checklist and Explanation. Ann. Intern. Med. 2018, 169, 467-473. [CrossRef]

24. Veritas Health Innovation. Covidence Systematic Review Software; Veritas Health Innovation: Melbourne, VIC, Australia, 2017.

25. Rafiei, A.; Amirrajab, N. Fungal Contamination of Indoor Public Swimming Pools, Ahwaz, South-West of Iran. Iran J. Public Health 2010, 39, 124-128.

26. Ekowati, Y.; Ferrero, G.; Kennedy, M.D.; de Roda Husman, A.M.; Schets, F.M. Potential Transmission Pathways of Clinically Relevant Fungi in Indoor Swimming Pool Facilities. Int. J. Hyg. Environ. Health 2018, 221, 1107-1115. [CrossRef]

27. Tlougan, B.E.; Mancini, A.J.; Mandell, J.A.; Cohen, D.E.; Sanchez, M.R. Skin Conditions in Figure Skaters, Ice-Hockey Players and Speed Skaters: Part II-Cold-Induced, Infectious and Inflammatory Dermatoses. Sports Med. 2011, 41, 967-984. [CrossRef]

28. Yenişehirli, G.; Karat, E.; Bulut, Y.; Savc1, U. Dermatophytes Isolated from the Mosques in Tokat, Turkey. Mycopathologia 2012, 174, 327-330. [CrossRef] [PubMed]

29. Watanabe, S.; Anzawa, K.; Mochizuki, T. High Prevalence of Superficial White Onychomycosis by Trichophyton Interdigitale in a Japanese Nursing Home with a Geriatric Hospital. Mycoses 2017, 60, 634-637. [CrossRef]

30. Kane, J.; Leavitt, E.; Summerbell, R.C.; Krajden, S.; Kasatiya, S.S. An Outbreak of Trichophyton Tonsurans Dermatophytosis in a Chronic Care Institution for the Elderly. Eur. J. Epidemiol. 1988, 4, 144-149. [CrossRef]

31. Müller, G. Occurrence of Dermatophytes in the Sands of European Beaches. Sci. Total Environ. 1973, 2, 116-118. [CrossRef]

32. Shimmura, Y. Isolation of Dermatophytes from Human Cases of Dermatophytosis and from House Dust. Jpn. J. Med. Mycol. 1985, 26, 74-80. [CrossRef]

33. Raboobee, N.; Aboobaker, J.; Peer, A.K.; Micro, M. Tinea Pedis et Unguium in the Muslim Community of Durban, South Africa. Int. J. Dermatol. 1998, 37, 759-765. [CrossRef]

34. Ingordo, V.; Naldi, L.; Fracchiolla, S.; Colecchia, B. Prevalence and Risk Factors for Superficial Fungal Infections among Italian Navy Cadets. Dermatology 2004, 209, 190-196. [CrossRef] [PubMed]

35. Uslu, H.; Uyanik, M.; Ayyildiz, A. Mycological Examination of the Barbers' Tools about Sources of Fungal Infections. Mycoses 2008, 51, 447-450. [CrossRef] [PubMed]

36. Pomeranz, A.J.; Sabnis, S.S.; McGrath, G.J.; Esterly, N.B. Asymptomatic Dermatophyte Carriers in the Households of Children with Tinea Capitis. Arch. Pediatr. Adolesc. Med. 1999, 153, 483-486. [CrossRef]

37. Tuknayat, A.; Bhalla, M.; Kaur, A.; Garg, S. Familial Dermatophytosis in India: A Study of the Possible Contributing Risk Factors. J. Clin. Aesthet. Dermatol. 2020, 13, 58-60.

38. Baumgardner, D.J. Fungal Infections From Human and Animal Contact. J. Patient-Cent. Res. Rev. 2017, 4, 78-89. [CrossRef]

39. Leelavathi, M.; Noorlaily, M. Onychomycosis Nailed. Malays Fam Physician 2014, 9, 2-7.

40. Jennings, M.B.; Pollak, R.; Harkless, L.B.; Kianifard, F.; Tavakkol, A. Treatment of Toenail Onychomycosis with Oral Terbinafine Plus Aggressive Debridement: IRON-CLAD, a Large, Randomized, Open-Label, Multicenter Trial. J. Am. Podiatr. Med. Assoc. 2006, 96, 465-473. [CrossRef]

41. Tanaka, K.; Katoh, T.; Irimajiri, J.; Taniguchi, H.; Yokozeki, H. Preventive Effects of Various Types of Footwear and Cleaning Methods on Dermatophyte Adhesion. J. Dermatol. 2006, 33, 528-536. [CrossRef]

42. Knudsen, E.A. Isolation of Dermatophytes from Footwear with Adhesive Tape Strips. J. Med. Vet. Mycol. 1987, 25, 59-61. [CrossRef]

43. Ajello, L.; Getz, M.E. Recovery of Dermatophytes from Shoes and Shower Stalls1. J. Investig. Dermatol. 1954, 22, 17-24. [CrossRef] 
44. Gupta, A.K.; Versteeg, S.G. The Role of Shoe and Sock Sanitization in the Management of Superficial Fungal Infections of the Feet. J. Am. Podiatr. Med. Assoc. 2019, 109, 141-149. [CrossRef]

45. Toukabri, N.; Dhieb, C.; El Euch, D.; Rouissi, M.; Mokni, M.; Sadfi-Zouaoui, N. Prevalence, Etiology, and Risk Factors of Tinea Pedis and Tinea Unguium in Tunisia. Can. J. Infect. Dis. Med. Microbiol. 2017, 2017, e6835725. [CrossRef]

46. De Boer, D.; Moriello, K. Cuteaneous Fungal Infections; Saunders Elsevier: Amsterdam, The Netherlands, 2006.

47. Oyeka, C.A.; Okoli, I. Isolation of Dermatophytes and Non-Dermatophytic Fungi from Soil in Nigeria. Mycoses 2003, 46, 318-320. [CrossRef] [PubMed]

48. Alter, S.J.; McDonald, M.B.; Schloemer, J.; Simon, R.; Trevino, J. Common Child and Adolescent Cutaneous Infestations and Fungal Infections. Curr. Probl. Pediatric Adolesc. Health Care 2018, 48, 3-25. [CrossRef]

49. Weese, J.S.; Fulford, M.B. Fungal Diseases. In Companion Animal Zoonoses; John Wiley \& Sons, Ltd.: Hoboken, NJ, USA, 2011; pp. 275-298, ISBN 978-0-470-95895-7.

50. Weitzman, I.; Summerbell, R.C. The Dermatophytes. Clin. Microbiol. Rev. 1995, 8, 240-259. [CrossRef]

51. Ara, K.; Hama, M.; Akiba, S.; Koike, K.; Okisaka, K.; Hagura, T.; Kamiya, T.; Tomita, F. Foot Odor Due to Microbial Metabolism and Its Control. Can. J. Microbiol. 2006, 52, 357-364. [CrossRef]

52. Hammer, T.R.; Mucha, H.; Hoefer, D. Infection Risk by Dermatophytes during Storage and after Domestic Laundry and Their Temperature-Dependent Inactivation. Mycopathologia 2011, 171, 43-49. [CrossRef]

53. Amichai, B.; Grunwald, M.H.; Davidovici, B.; Farhi, R.; Shemer, A. The Effect of Domestic Laundry Processes on Fungal Contamination of Socks. Int. J. Dermatol. 2013, 52, 1392-1394. [CrossRef]

54. Brunton, W.A. Infection and Hospital Laundry. Lancet 1995, 345, 1574-1575. [CrossRef]

55. Fijan, S.; Šostar-Turk, S.; Cencič, A. Implementing Hygiene Monitoring Systems in Hospital Laundries in Order to Reduce Microbial Contamination of Hospital Textiles. J. Hosp. Infect. 2005, 61, 30-38. [CrossRef]

56. Flores, J.M.; Castillo, V.B.; Franco, F.C.; Huata, A.B. Superficial Fungal Infections: Clinical and Epidemiological Study in Adolescents from Marginal Districts of Lima and Callao, Peru. J. Infect. Dev. Ctries 2009, 3, 313-317. [CrossRef] [PubMed]

57. Marchisio, V.F.; Preve, L.; Tullio, V. Fungi Responsible for Skin Mycoses in Turin (Italy). Mycoses 1996, 39, 141-150. [CrossRef]

58. Tan, J.S. Human Zoonotic Infections Transmitted by Dogs and Cats. Arch. Intern. Med. 1997, 157, 1933-1943. [CrossRef] [PubMed]

59. McAleer, R. Fungal Infection as a Cause of Skin Disease in Western Australia. Australas. J. Dermatol. 1981, 22, 80-84. [CrossRef]

60. Nenoff, P.; Krüger, C.; Ginter-Hanselmayer, G.; Tietz, H.-J. Mycology_An Update. Part 1: Dermatomycoses: Causative Agents, Epidemiology and Pathogenesis. JDDG J. Dtsch. Dermatol. Ges. 2014, 12, 188-210. [CrossRef]

61. Kraemer, A.; Hein, J.; Heusinger, A.; Mueller, R.S. Clinical Signs, Therapy and Zoonotic Risk of Pet Guinea Pigs with Dermatophytosis. Mycoses 2013, 56, 168-172. [CrossRef]

62. Bartosch, T.; Frank, A.; Günther, C.; Uhrlaß, S.; Heydel, T.; Nenoff, P.; Baums, C.G.; Schrödl, W. Trichophyton Benhamiae and T. Mentagrophytes Target Guinea Pigs in a Mixed Small Animal Stock. Med. Mycol. Case Rep. 2019, 23, 37-42. [CrossRef]

63. Segal, E.; Elad, D. Human and Zoonotic Dermatophytoses: Epidemiological Aspects. Front. Microbiol. 2021, 12, 713532. [CrossRef]

64. Dupont, D.; Peyron, F.; Picot, S.; Wallon, M.; Bienvenu, A.-L. Dermatophytes and Transmission Risks to Family: A Retrospective Study of a Cohort of 256 Adopted Children from 1998 to 2012. Pediatr. Dermatol. 2015, 32, 426-427. [CrossRef]

65. Jang, K.-A.; Chi, D.-H.; Choi, J.-H.; Sung, K.-J.; Moon, K.-C.; Koh, J.-K. Tinea Pedis in Korean Children. Int. J. Dermatol. 2000, 39, 25-27. [CrossRef] [PubMed]

66. Lim, S.S.; Ohn, J.; Mun, J.-H. Diagnosis of Onychomycosis: From Conventional Techniques and Dermoscopy to Artificial Intelligence. Front. Med. 2021, 8, 637216. [CrossRef] 